\title{
Human Cancer Viruses
}




\section{Translational Research in Biomedicine Vol. 1}

Series Editor

Samuel H.H. Chan Kaohsiung

Associate Editor

Julie Y.H. Chan Kaohsiung 


\section{Human Cancer Viruses}

\section{Principles of Transformation and Pathogenesis}

Volume Editors

John Nicholas Baltimore, Md.

Kuan-Teh Jeang Bethesda, Md.

T.-C. Wu Baltimore, Md.

35 figures, 9 in color, and 9 tables, 2008 


\section{Translational Research in Biomedicine}

\author{
John Nicholas, PhD \\ Viral Oncology Program \\ Sidney Kimmel Comprehensive Cancer Center \\ Johns Hopkins University \\ Baltimore, MD 21287 (USA)
}

\section{T.-C. Wu, MD, PhD \\ Department of Pathology \\ Johns Hopkins School of Medicine \\ Cancer Research Building II, Room 309 \\ Baltimore, MD 21231 (USA)}

Kuan-Teh Jeang, MD, PhD Laboratory of Molecular Microbiology National Institute of Allergy and Infectious Diseases

National Institute of Health

Bethesda, MD 20892 (USA)

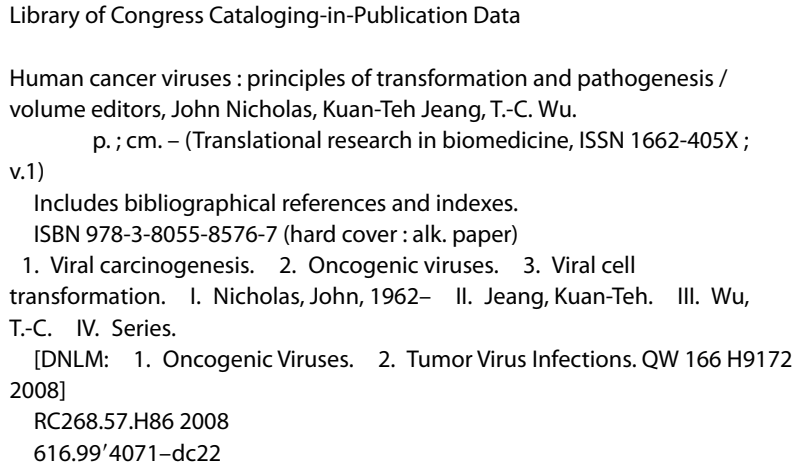

2008019369

Disclaimer. The statements, options and data contained in this publication are solely those of the individual authors and contributors and not of the publisher and the editor(s). The appearance of advertisements in the book is not a warranty, endorsement, or approval of the products or services advertised or of their effectiveness, quality or safety. The publisher and the editor(s) disclaim responsibility for any injury to persons or property resulting from any ideas, methods, instructions or products referred to in the content or advertisements.

Drug Dosage. The authors and the publisher have exerted every effort to ensure that drug selection and dosage set forth in this text are in accord with current recommendations and practice at the time of publication. However, in view of ongoing research, changes in government regulations, and the constant flow of information relating to drug therapy and drug reactions, the reader is urged to check the package insert for each drug for any change in indications and dosage and for added warnings and precautions. This is particularly important when the recommended agent is a new and/or infrequently employed drug.

All rights reserved. No part of this publication may be translated into other languages, reproduced or utilized in any form or by any means electronic or mechanical, including photocopying, recording, microcopying, or by any information storage and retrieval system, without permission in writing from the publisher.

(c) Copyright 2008 by S. Karger AG, P.O. Box, CH-4009 Basel (Switzerland)

www.karger.com

Printed in Switzerland on acid-free and non-aging paper (ISO 9706) by Reinhardt Druck, Basel

ISSN 1662-405X

ISBN 978-3-8055-8576-7 


\section{Contents}

VII Foreword

Chan, S.H.H. (Kaohsiung)

Ix Preface

Nicholas, J. (Baltimore, Md.); Jeang, K.-T. (Bethesda, Md.); Wu, T.-C. (Baltimore, Md.)

1 Molecular Epidemiology of Human Papillomavirus Infection

Gillison, M.L. (Baltimore, Md.)

20 Molecular Pathogenesis of the Human Papillomavirus: Cervical Cancer as a Model Mao, C.-P.; Wu, T.-C. (Baltimore, Md.)

37 Human Papillomavirus Vaccines

Roden, R.; Hung, C.-F.; Monie, A.; Wu, T.-C. (Baltimore, Md.)

63 Hepatitis C Virus Genetics and the Discovery of MechanismBased Inhibitors of the NS3/4A Protease and NS5B Polymerase LaFemina, R.L. (Schwenksville, Pa.)

94 Role of the Hepatitis B Virus in Hepatocellular Carcinoma Toh, S.-T.; Lee, C.G. (Singapore)

108 Carcinogenesis Induced by Hepatitis B Virus

Cougot, D.; Buendia, M.-A.; Neuveut, C. (Paris)

137 Disease and Pathogenesis Associated with Epstein-Barr Virus Ambinder, R.F. (Baltimore, Md.)

150 The Biology and Molecular Biology Underlying Epstein-Barr Virus Oncogenesis

Martin, H.J.; Hayward, S.D. (Baltimore, Md.)

170 Kaposi-Sarcoma-Associated Herpesvirus

Clinical Diseases and Viral Pathogenesis

Damania, B.; Dittmer, D.P. (Chapel Hill, N.C.)

186 Molecular Biology of Human Herpesvirus 8 Neoplasia

Chaudhary, P.M. (Pittsburgh, Pa.); Nicholas, J. (Baltimore, Md.) 
211 Human T Cell Leukemia Virus Type 1 and 2: Mechanisms of Pathogenesis Arnold, J.; Green, P.L. (Columbus, Ohio)

228 Chromosomal Instability and Human T Cell Leukemia Virus 1 Transformation

Chi, Y.-H.; Jeang, K.-T. (Bethesda, Md.)

239 Author Index

240 Subject Index 


\section{Foreword}

Welcome to Translational Research in Biomedicine, a new book series dedicated to the dissemination of seminal information in contemporary biomedicine with a translational orientation.

Translational research (TR) is now a household word in the arena of contemporary biomedical research, although a universal definition for this term is currently wanting. In a more restricted sense, TR is often associated with research and development based on the classical bench to bedside approach. Thus, it has been said that 'the goal of TR is to implement in vivo measurements and leverage preclinical models that more accurately predict drug effects in humans' [1]; or 'TR describes a uni-directional effort to test in humans novel therapeutic strategies developed through experimentation' [2]. The current enthusiasm for the application of genomic or stem cell research to therapeutic strategies is also grounded on a similar premise. In a broader sense, TR is taken as a bench to bedside and back approach to foster communication between the scientific community and clinical practitioners [1]. It is a concept that needs the attention from everyone and should be the foundation of a modern understanding of health provision [3].

If we subscribe to the philosophical connotation that medical research is for the betterment of humankind, then we should realize that there is no real demarcation between clinical (bedside) and preclinical (bench) research. This is because the only difference is that human subjects instead of animals, tissues or cells are employed in the studies. Nonetheless, governed by the same ethical principles and guidelines, all of them will reveal information in some aspects of biomedicine. Thus, this monograph series shall take a holistic view on TR that transcends the boundaries between bench and bedside research. Each volume shall be a synthesis of ideas, technologies and research outcomes that are associated with a particular theme in contemporary biomedicine, to be edited by experts in that field. Some chapters may be up-to-date reviews on fundamental 
principles that underlie this theme, to be followed by their clinical applications. Other chapters may begin with clinical observations on this theme, to be followed by their underlying cellular and molecular mechanisms. The word 'translation' is most commonly defined as expression of words in another language. Its definitions can be extended to encompass expression in simpler language and uncomplicated interpretation. In this spirit, all volumes in this series will be presented in a fashion that is amenable to nonexperts, be they scientists or clinical practitioners.

My sincere thanks go to Drs. John Nicholas, Kuan-Teh Jeang and T.-C. Wu, Editors for this inaugural volume, for their unfailing efforts to make this series a reality. I am particularly in debt to Dr. Jeang for his timely advice during the planning stage of this project. I also wish to acknowledge the capable hands of Rolf Steinebrunner, Stefan Goldbach and Esther Bernhard at S. Karger AG during the development and production of this series. Last but not least, the publication of Translational Research in Biomedicine would not have been possible without the foresight, enthusiasm and whole-hearted support of my dear friend, Dr. Thomas Karger.

Samuel H.H. Chan

Series Editor

1 Hörig H, Pullman W: From bench to clinic and back: perspective on the 1st IQPC Translational Research Conference. J Transl Med 2004;2:44-51.

2 Mankoff SP, Brander B, Ferrone S, Marincola FM: Lost in translation: obstacles to translational medicine. J Transl Med 2004;2:14-18.
Sonntag KC: Implementations of translational medicine. J Transl Med 2005;3:33-35. 


\section{Preface}

The genesis of this book stems from a long-standing collaboration between many of its authors in the teaching of viral oncology to postgraduate students at the Johns Hopkins School of Medicine. Recognizing that a number of these students had little or no exposure to the history, landmark contributions or current research in this important and exciting field was the prime motivation for teaching the course and, subsequently, for compiling this book. Studies of human and nonhuman oncogenic viruses have made enormous contributions to our understanding of crucially important aspects of cell biology and transformation. For many of us who have lived through pivotal advances in viral oncology over the past 4 decades, there is a strong desire, perhaps a feeling of obligation, to share the past and present excitement of the field with a new generation of scientists. This, along with the wish to present a review of human viral oncology as a cohesive topic, represents the mission of this book.

The first identification of a tumor-causing virus, Rous sarcoma virus, occurred almost 100 years ago, but it was not until the 1970s that the genetic basis for oncogenesis by this and other acutely transforming retroviruses of avian and rodent species was appreciated. Numerous viral oncogenes and their corresponding cellular protooncogene counterparts were identified in rapid succession from these altered and defective viruses. These studies launched a new era of research forging insight into the basic mechanisms of cell cycle control and the functions of key genes involved in its regulation. Later studies of DNA tumor viruses simian virus 40 and human adenovirus, found to be transforming in culture and animal models, provided the next advances in our understanding of viral oncogenesis and virus manipulation of the cell cycle and cell survival. These viruses served as crucially important models for the study of oncogenesis, linking processes normally utilized by viruses for replication to mechanisms of oncogenesis occurring under conditions nonpermissive to productive replication. The importance of these discoveries to the elucidation of normal cellular 
control pathways and the aberrancies occurring in nonvirally associated as well as virus-induced cancers is difficult to overstate. They exemplify what all virologists know to be true, that viruses, by virtue of evolutionary selection processes, target and manipulate centrally important cellular control pathways by elegantly efficient means that can be utilized by the experimental biologist to elucidate their architecture. It is entirely understandable, then, that $\mathrm{p} 53$ and $\mathrm{E} 2 \mathrm{~F}$ and $\mathrm{Rb} / \mathrm{E} 2 \mathrm{~F}$ associations, for example, were first identified via the study of viruses and viral proteins, SV40 T-Ag and adenovirus E1A, respectively.

Viruses are not only tools for discoveries in cell and molecular biology. However, they are worthy research objects in their own right, not least because they are significant pathogens, including oncogenic agents in humans. Leaving aside the unresolved (and often contentious) issue of the potential role of polio-vaccine-introduced SV40 in human malignancies, there are several human viruses that are strongly associated epidemiologically with human cancers and that represent significant health concerns. However, from the high infection rates of these viruses coupled with the relatively low incidence of virus-associated cancers, it is evident that oncogenic transformation is not part of the normal life cycle of these viruses. In addition to virus exposure, predisposing cofactors can include immunosuppression, host genetics and particular environmental criteria. This highlights the multifactorial, multistep nature of viral oncogenesis in the natural host, the viral agent being a necessary or contributory factor but clearly not the only one. The relevant viruses with regard to human cancers are human T lymphotropic virus 1, human papillomavirus, hepatitis viruses B and C, and the human $\gamma$-herpesviruses Epstein-Barr virus and human herpesvirus 8 (also called Kaposi's sarcoma-associated virus); these comprise the focus of this book. The particular mechanisms relevant to transformation by these viruses are varied, but all appear to involve the influence of viral proteins whose roles are to provide the conditions for efficient virus productive replication or, in the case of Epstein-Barr virus and human herpesvirus 8 at least, for the maintenance of the latently infected cell pools. Understanding the mechanisms leading to cellular transformation and oncogenesis by these viruses, in addition to the roles of particular viral proteins in these processes and the normal virus life cycle, is essential for the development of highly directed and specific therapeutic and antiviral treatments. This said, it is also evident that vaccination to prevent primary infection by oncogenic viruses can provide a means of eliminating the possibility of cancers in which viruses play a necessary role. Cancer vaccination is already here with regard to the $70 \%$ of cervical carcinomas caused by human papillomavirus types 16 and 18 , and further research is ongoing to utilize protein- and DNA-based vaccines to provide broadly based protection against all oncogenic human papillomaviruses. Similar strategies could conceivably be used for tackling cancers caused by other viruses, although this is easier said than done.

This book provides a comprehensive overview of the human oncogenic viruses, with respect to their molecular biology and epidemiology and to clinical aspects of disease, therapy and prevention. As outlined in the chapters collated here, work on 
these viruses has greatly aided our appreciation of the diversity and details of mechanisms likely to be involved in oncogenesis as well as virus biology and has, along the way, revealed new paradigms in cell and molecular biology. These human oncogenic viruses, then, join their historical predecessors in serving as tools for understanding normal cell regulatory processes. It seems evident that further seminal discoveries of general import will be made through the study of these significant human pathogens, and that such study will also provide the means to prevent and treat associated human disease.

John Nicholas, Kuan-Teh Jeang and T.-C. Wu Volume Editors 
